\title{
Geographic variation in natal and early larval trace-elemental signatures in the statoliths of the market squid Doryteuthis (formerly Loligo) opalescens
}

\author{
Robert R. Warner ${ }^{1,2, *}$, Scott L. Hamilton ${ }^{2}$, Michael S. Sheehy ${ }^{2}$, Louis D. Zeidberg ${ }^{3}$, \\ Briana C. Brady ${ }^{4}$, Jennifer E. Caselle ${ }^{2}$

\begin{abstract}
${ }^{1}$ Department of Ecology, Evolution and Marine Biology, University of California, Santa Barbara, California 93106-9610, USA
${ }^{2}$ Marine Science Institute, University of California, Santa Barbara, California 93106-6150, USA

${ }^{3}$ Ecology and Evolutionary Biology, University of California, Los Angeles, California 90095-1606, USA

${ }^{4}$ California Department of Fish and Game, Marine Region, 1933 Cliff Drive, Suite 9, Santa Barbara, California 93109, USA
\end{abstract}

\begin{abstract}
We found distinct geographic differences in trace element concentrations in both the core and early larval areas of the statoliths of paralarval market squid Doryteuthis $(=$ Loligo) opalescens at sites throughout the Southern California Bight, USA. Laser ablation inductively coupled plasma mass spectrometry (LA-ICPMS) of individual statoliths indicated detectable levels of $\mathrm{Mg}, \mathrm{Mn}, \mathrm{Sr}$, and $\mathrm{Ba}$, with marginal levels of $\mathrm{Cr}$ and $\mathrm{Pb}$. While these paralarvae showed considerable within-sample differences in elemental concentrations, there was significant between-site discrimination of natal (core) and early larval signatures for collection sites up to $100 \mathrm{~km}$ apart. In 2002 and 2003, levels of Ba and Sr in the statolith cores were significantly different among sites, suggesting differences in the natal environment or local maternal effects. Site specific differences in elemental signatures were also apparent for $\mathrm{Mg}$ and $\mathrm{Mn}$ in samples taken from outside the core in the early posthatching period. These same portions of the statolith can be analyzed from adult squid collected on spawning grounds. We showed that concentrations of trace elements in the statolith cores of adults closely resembled the core signatures of squid paralarvae, which opens the possibility of identifying the source populations for stocks of this commercially important species.
\end{abstract}

KEY WORDS: Market squid · Statoliths · Mass spectrometry · Larvae · Natal signatures · Doryteuthis opalescens

Resale or republication not permitted without written consent of the publisher

\section{INTRODUCTION}

The California market squid Doryteuthis (formerly Loligo) opalescens (see Anderson 2000 for genus reclassification) has been the largest fishery in the state of California in terms of volume and value for most of the last $15 \mathrm{yr}$ (Sweetnam 2006). A purse seine fishery captures spawning adults as they aggregate to mate and lay their eggs on sandy-bottoms in shelf waters $<100 \mathrm{~m}$ deep. Since the early 1980s, an increasing proportion of the statewide landings have come from southern California (Vojkovich 1998), mainly around the Channel Islands and nearby submarine canyons. Currently, the fishery is managed throughout the state as one homogenous population (CDFG 2005). To date, genetic studies (Reichow \& Smith 2001, W. F. Gilly unpubl. data) have noted homogeneity in the populations from Alaska to Baja California, but this could be the result of a relatively low migration rate between otherwise isolated populations. Morphometrics and allozyme analyses were equally ambiguous (Ally \& Keck 1978, Christofferson et al. 1978, Kashiwada \& Recksiek 1978). Fishery independent data suggest that this squid occurs in many areas along the 
Pacific coast besides the primary locations targeted by the fishery (Reiss et al. 2004). However, an important question remains: Do individual spawning squid tend to return to their natal areas, or are stocks indeed well mixed?

This paper investigates the applicability of using natal trace element signatures in the statoliths of market squid to identify the geographic location of origin. We did this by analyzing the cores and early larval portions of statoliths of paralarvae captured in different areas off southern California. Statoliths are composed of calcium carbonate crystals (as aragonite) within a protein matrix. Development is temperature dependent and statoliths are formed $9 \mathrm{~d}$ post-fertilization at $16^{\circ} \mathrm{C}$ (Fields 1965). After hatching, statoliths grow daily as new crystal layers are deposited around the existing core (Lipinski 1993). Trace element analysis of otoliths, a similar calcium carbonate structure in fish, has been used for many years to demonstrate population structure (Campana 1999, Campana \& Thorrold 2001, Thorrold et al. 2002). Recently, natal (i.e. birthplace) signatures and population structure have been inferred from microchemical analyses of the statoliths and hard parts of other mollusks (Zacherl et al. 2003b, Zacherl 2005, Becker et al. 2005, Doubleday et al. 2008).

As with gastropods, there is accumulating evidence suggesting that the chemical composition of squid statoliths could be useful as a natural tag of dispersal and movement patterns. For example, oxygen isotopes in squid statoliths are deposited in equilibrium with ambient waters (Radtke 1983). Variation in strontium (Sr) concentrations within statoliths track squid in ontogenetic migrations (Yatsu et al. 1998, Ikeda et al. 2003, Zumholz et al. 2007), vertical diel migrations (Ikeda et al. 1998, Bettencourt \& Guerra 2000), and daily feeding activities (Ikeda et al. 2002a). Recent work has also indicated distinct seasonal, developmental, and spatial patterns of chemical signatures in statoliths of Doryteuthis (= Loligo) gahi in the south Atlantic (Arkhipkin et al. 2004).

If trace elements from the surrounding waters substitute for calcium in the matrix of the statolith, their concentration may reflect differences in the physical characteristics and elemental composition of the water mass in which they were formed (Zacherl et al. 2003a; for otoliths, see Secor et al. 1995, Bath et al. 2000, Elsdon \& Gillanders 2002). Thus, statoliths formed while larval squid are at or near the spawning site potentially carry a natural record of the site of origin (i.e. a natal signature). However, the dynamics of incorporation of trace elements into the hard parts of organisms are complex (Campana 1999, Elsdon \& Gillanders 2003), and statolith chemistry may not necessarily be a strict reflection of the physical and chemical properties of the surrounding seawater (see Warner et al. 2005 for an otolith example). It is also becoming increasingly apparent that there are strong maternal effects on element incorporation into the natal portion of otoliths (Warner et al. 2005, Thorrold et al. 2006) and statoliths (Lloyd et al. 2008). In some cases, problems in predicting elemental incorporation can be avoided by microchemical evaluation of the hard structures of young squid while they are still resident in source populations and through subsequent evaluation of the same structure in cohorts after dispersal (e.g. Thorrold et al. 2001).

Many open-coast dwelling marine animals begin forming their statoliths or otoliths while still in the egg, before they begin their pelagic phase (Hanlon et al. 1989, Jones et al. 1999). For these organisms, the core of the statolith or otolith should contain a natal signature. Zacherl et al. (2003b) recently showed evidence for geographical variation in natal elemental signatures of statoliths of encapsulated veliger larvae from the open-coast mollusk Concholepas concholepas. Significant spatial discrimination of natal chemical signatures has also been reported for the gastropod Kelletia kelletii along the California coast (Zacherl 2005). In this paper, we demonstrate that natal signatures can be analyzed from the statoliths of market squid paralarvae, and we also explore whether paralarvae captured at one site can be distinguished chemically from paralarvae captured at other sites. Finally, we demonstrate that the paralarval segment (i.e. core) of an adult statolith can be analyzed, and that average trace element concentrations in this segment of the statolith are equivalent to that seen in paralarvae.

\section{MATERIALS AND METHODS}

Study species. Market squid spawn throughout the year along the California coast. Primary spawning events occur during the winter in southern California and in the summer in Monterey Bay, which are the 2 major target locations for the fishery. The paralarvae hatch from egg cases, anchored by the mother into sandy habitat after about 7 wk (L. D. Zeidberg unpubl. data). Paralarvae may be entrained within $3 \mathrm{~km}$ offshore for periods of weeks in the convergence zones created by tidal and neritic currents (Zeidberg \& Hamner 2002). At $15 \mathrm{~mm}$ mantle length (ML), juveniles appear to develop the capability to swim in schools and against horizontal currents (Hurley 1977, Yang et al. 1986). The 55 to $85 \mathrm{~mm}$ ML size cohort is absent from shelf waters (Zeidberg 2004), and full-sized adults migrate to the shelf to spawn near the end of their life span (Macewicz et al. 2004), which has been estimated at between 4 to 9 mo (average $6 \mathrm{mo}$ ) using statolith 
Table 1. Doryteuthis opalescens. Sampling scheme for paralarvae. Numbers included in particular analyses depended on samples with detectable levels of trace elements

\begin{tabular}{|c|c|c|c|c|c|c|}
\hline Date & $\begin{array}{l}\text { Sample } \\
\text { ID }\end{array}$ & $\begin{array}{c}\text { No. } \\
\text { processed }\end{array}$ & $\begin{array}{l}\text { Temp. } \\
\left({ }^{\circ} \mathrm{C}\right)\end{array}$ & $\begin{array}{l}\text { Depth } \\
\text { (m) }\end{array}$ & Location & Coordinates \\
\hline \multicolumn{7}{|l|}{2002} \\
\hline $11 \mathrm{Feb}$ & SBI & 9 & 13.6 & 25.5 & East Santa Barbara Island & $33^{\circ} 27.681^{\prime} \mathrm{N}, 119^{\circ} 0.639^{\prime} \mathrm{W}$ \\
\hline $12 \mathrm{Feb}$ & SBI-Cat & 8 & 11.8 & 61.9 & Between Santa Barbara and Catalina Island & $33^{\circ} 26.107^{\prime} \mathrm{N}, 118^{\circ} 41.867^{\prime} \mathrm{W}$ \\
\hline $12 \mathrm{Feb}$ & Cat & 12 & 12.4 & 51.0 & Catalina Island Harbor & $33^{\circ} 25.126^{\prime} \mathrm{N}, 118^{\circ} 32.433^{\prime} \mathrm{W}$ \\
\hline \multicolumn{7}{|l|}{2003} \\
\hline 6 Feb & Red & 5 & 14.3 & 23.0 & Redondo Canyon & $33^{\circ} 48.914^{\prime} \mathrm{N}, 118^{\circ} 25.828^{\prime} \mathrm{W}$ \\
\hline 4 Feb & SCC-E & 20 & $13.8^{\mathrm{a}}$ & $43.0^{\mathrm{a}}$ & Santa Cruz Channel & $33^{\circ} 56.466^{\prime} \mathrm{N}, 119^{\circ} 50.751^{\prime} \mathrm{W}$ \\
\hline 4 Feb & $\mathrm{SCC}-\mathrm{C}$ & 8 & $13.8^{\mathrm{a}}$ & $43.0^{\mathrm{a}}$ & Santa Cruz Channel & $33^{\circ} 58.560^{\prime} \mathrm{N}, 119^{\circ} 54.788^{\prime} \mathrm{W}$ \\
\hline 4 Feb & SCC-W & 10 & $13.8^{\mathrm{a}}$ & $43.0^{\mathrm{a}}$ & Santa Cruz Channel & $33^{\circ} 56.741^{\prime} \mathrm{N}, 119^{\circ} 55.864^{\prime} \mathrm{W}$ \\
\hline
\end{tabular}

increment counts (Butler et al. 1999, Jackson \& Domeier 2003). This lessthan-annual lifespan raises an important question: What are the origins of the spawning aggregations that are fished on an annual basis in northern and southern California?

Sampling location. Sampling was conducted in 2002 and 2003 in the Southern California Bight, $33^{\circ}$ to $34^{\circ} \mathrm{N}$, $118^{\circ}$ to $121^{\circ} \mathrm{W}$ (Table 1, Fig. 1). Paralarvae were collected with a $1 \mathrm{~m}$ Bongo net with $505 \mu \mathrm{m}$ mesh. Differential global positioning system (GPS) data were recorded for each tow to measure the distances sampled. Tow surveys were conducted in 15 min double-oblique casts (the net descends and returns at an angle) to sample the deepest depth possible without touching the bottom, within the 25 to $130 \mathrm{~m}$ isobaths. Samples with sufficient numbers of squid paralarvae were selected for statolith analysis (Table 1, Fig. 1). Collection sites for 2003 were sometimes grouped by region, since 3 of the samples were collected in the Santa Cruz Channel on the same day. Samples of adult squid were collected in 2001 from commercial fishermen by the California Department of Fish and Game (CDFG). Samples were collected from 2 CDFG fishing record blocks, one south of Santa Rosa Island and one south of Catalina Island in the spring of 2001 (Fig. 1).

Sample preparation. Plankton samples including squid paralarvae were concentrated and frozen aboard the research vessel. After thawing in the laboratory

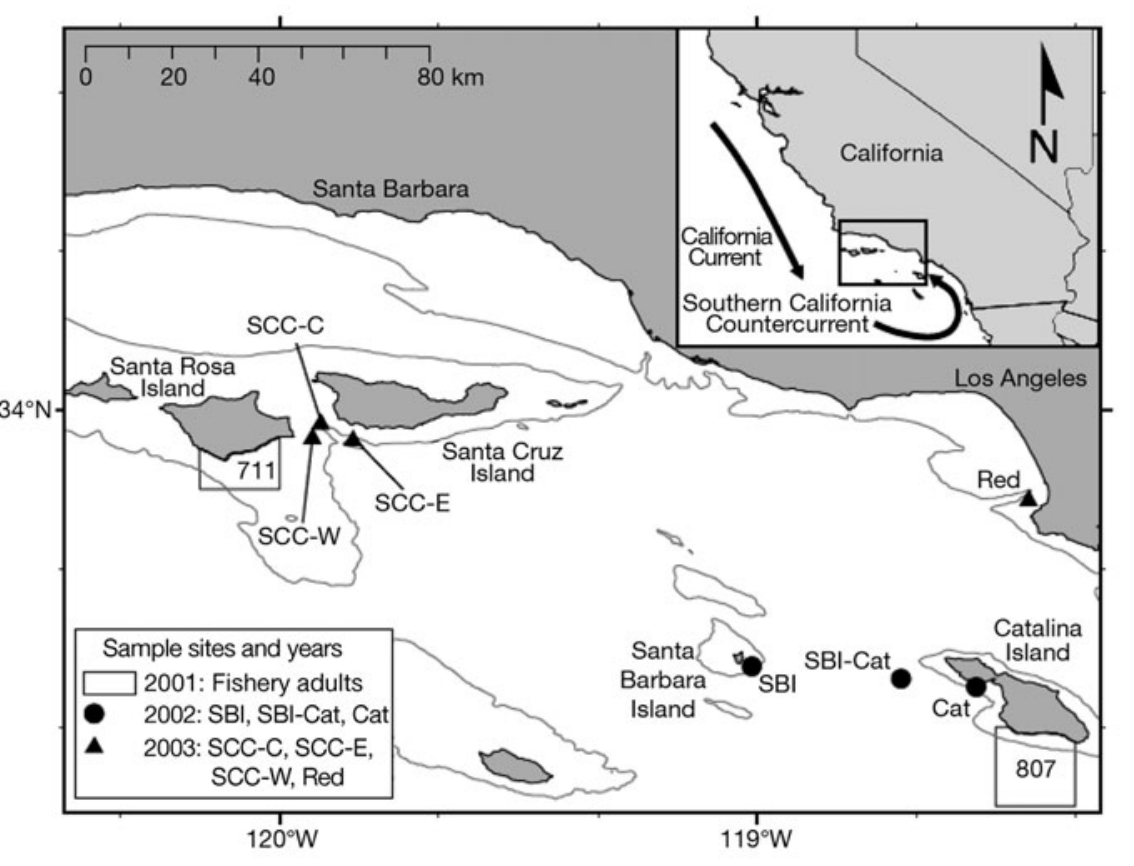

Fig. 1. Doryteuthis opalescens. Map depicting sample sites of paralarval collections in 2002 (SCC-C, SCC-E, SCC-W, Red) and 2003 (SBI, SBI-Cat, Cat) (see Table 1 for details). The boxes south of Santa Rosa and Catalina Island indicate the number of adults caught by fisheries in 2001. Thin gray lines depict the $200 \mathrm{~m}$ isobath. Southern California waters have a complex physical oceanography dominated by the equatorward flow of the California Current (CC) and poleward flow of the Southern California Eddy (SCE) or Countercurrent (depicted by thick arrows in map inset). Waters of the SCE are warmer, saltier, and less productive. The western Channel Islands are dominated by the CC, while the SCE bathes the eastern Channel Islands. The central Channel Islands are intermediate with transient wind patterns dictating which of the major currents (CC or SCE) are predominant. The bottom topography from the array of islands in the Southern California Bight creates complex mesoscale circulation patterns, including eddies and fronts that lead to areas of retention and advection of planktonic organisms

and isolating squid paralarvae, statoliths were dissected and stored dry. Statoliths were removed from adult samples and stored similarly. One statolith from each individual was mounted on an acrylic slide with 
low viscosity epoxy resin (Epo-Thin, Buehler). To expose the areas of interest, each statolith was polished to within 10 to $20 \mu \mathrm{m}$ of the core using a lapping wheel and $9 \mu \mathrm{m}$ and $3 \mu \mathrm{m} 3 \mathrm{M}^{\circledR}$ diamond polishing film. To remove contaminants and minimize the organic contribution prior to analysis, mounted statoliths were rinsed in ultra pure water ( $\mathrm{N}$-pure, resistivity $>18.1 \mathrm{M} \Omega$ ), soaked in semiconductor grade $15 \% \mathrm{H}_{2} \mathrm{O}_{2}$ buffered with Suprapur $0.05 \mathrm{~N} \mathrm{NaOH}$ in acid-leached plastic trays for $1 \mathrm{~h}$, rinsed again in $\mathrm{N}$-pure, soaked and rinsed 5 times in $\mathrm{N}$-pure for $5 \mathrm{~min}$, rinsed a final time with $\mathrm{N}$-pure and air dried in a Class-100 laminar flow bench.

Sample elemental analysis. To determine whether statoliths of paralarvae bore a distinctive natal or early-larval signature, we compared element(metal)/calcium (Me/Ca) ratios of paralarval statoliths from different sites and regions. We also compared the cores of adult squid statoliths with the same area of paralarval statoliths to establish that the elemental concentrations were similar.

Since our collections were of pelagic paralarvae, 2 regions of the statolith were available for analysis (Fig. 2). The trace elements in the core region were incorporated while the embryo was still in the egg capsule, representing a natal signature (i.e. record of chemical signature of birthplace). Natal signatures may represent maternal effects (that is, trace elements passed through the yolk), true local effects from the surrounding water that diffuses into the egg capsules during ontogeny, or a combination of both. The second pit is formed during early pelagic life and should register environmental rather than maternal effects, since the yolk is utilized in the first 4 to $6 \mathrm{~d}$ post-hatching (Vidal et al. 2002). Information from the 2 statolith regions, combined with the collection location, can provide information about geographical signatures and larval movement.

Statoliths were analyzed on a Finnigan MAT Element 2 sector field inductively coupled plasma mass spectrometer (ICPMS). The element menu included magnesium (Mg), calcium $(\mathrm{Ca})$, chromium $(\mathrm{Cr})$, manganese $(\mathrm{Mn})$, strontium $(\mathrm{Sr})$, barium $(\mathrm{Ba})$, and lead $(\mathrm{Pb})$. Sample introduction was by laser ablation using a VG-UV microprobe Nd:YAG laser system, frequencyquadrupled to $266 \mathrm{~nm}$ with a nominal beam width of $20 \mu \mathrm{m}$. Our LA-ICPMS parameters and material introduction methods follow those described for otolith elemental analysis in Ruttenberg et al. (2005) and Warner et al. (2005). Ablated material was mixed with $1 \%$ $\mathrm{HNO}_{3}$ and aspirated using a low flow nebulizer (50 $\mathrm{\mu l}$ $\min ^{-1}$ ) to create wet plasma conditions.

We collected sequential, discrete ablations in a vertical transect through the 2 different locations (i.e. core and 2nd pit) on each statolith (Fig. 2). Each ablation pit in a vertical transect consisted of 8 laser pulses of $0.1 \mathrm{~mJ}$ at $3 \mathrm{~Hz}$ and averaged $26 \mu \mathrm{m}$ in diameter and $\sim 10 \mu \mathrm{m}$ in depth. For each ablation, we collected the isotopes ${ }^{24} \mathrm{Mg},{ }^{48} \mathrm{Ca},{ }^{52} \mathrm{Cr},{ }^{55} \mathrm{Mn},{ }^{86} \mathrm{Sr}{ }^{87} \mathrm{Sr},{ }^{138} \mathrm{Ba}$, and ${ }^{208} \mathrm{~Pb}$. We switched from collecting the isotope ${ }^{86} \mathrm{Sr}$ to collecting ${ }^{87} \mathrm{Sr}$ halfway through the study due to a second argon gas source being contaminated with gas interference for ${ }^{86} \mathrm{Sr}$. All isotopes were determined using medium resolution mode $(\mathrm{R}=300)$ due to isotopic interferences for some analytes of interest. Molar $\mathrm{Me} / \mathrm{Ca}$ ratios were calculated for each ablation using the isotopic intensity ratios and the elemental mass biases determined by sampling calibration standard solutions before and after every 3rd statolith.

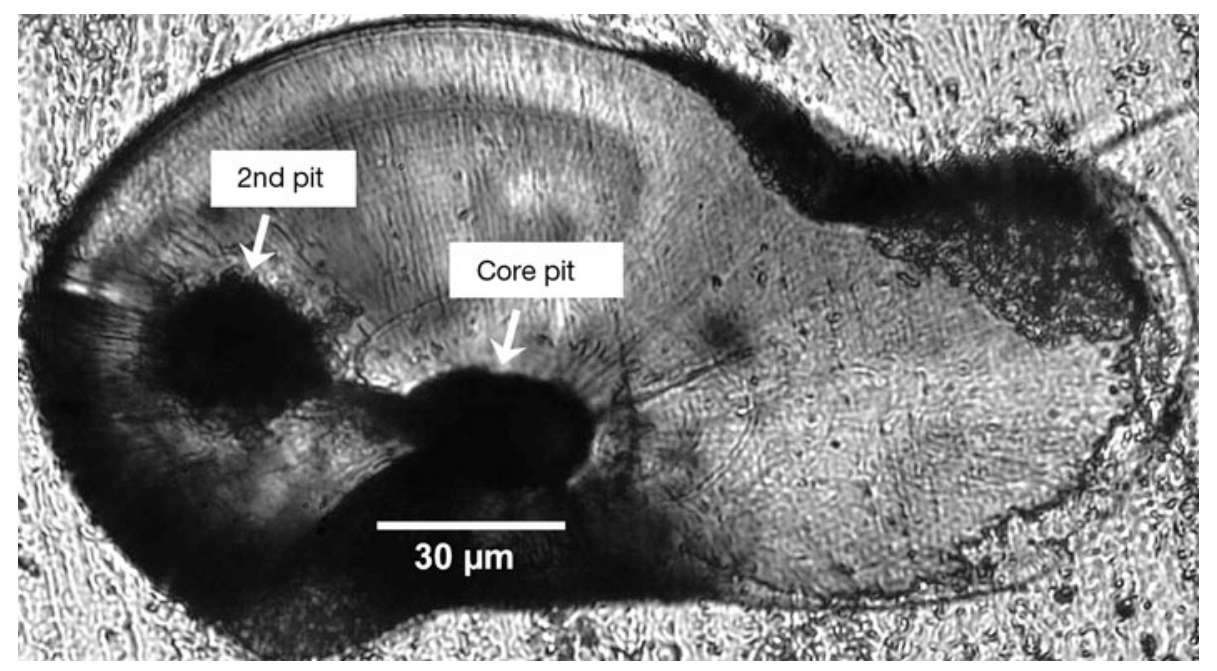

Fig. 2. Doryteuthis opalescens. Image of a paralarval statolith. Shown are the core (natal portion) and 2nd (early larval portion) ablation pits from LA-ICPMS analyses. Daily statolith growth increments are also visible 
We estimated the accuracy of the analytical method throughout the study by ablating a solid glass reference material from the US National Institute of Standards and Technology (NIST 612) at the beginning and end of each day of analysis. These precision estimates, described as \%RSD (\% relative standard deviation), averaged $15.8 \%$ for $\mathrm{Mg} / \mathrm{Ca}, 12.2 \%$ for $\mathrm{Cr} / \mathrm{Ca}, 17.3 \%$ for $\mathrm{Mn} / \mathrm{Ca}, 25.7 \%$ for $\mathrm{Sr} / \mathrm{Ca}, 13.1 \%$ for $\mathrm{Ba} / \mathrm{Ca}$, and $15.1 \%$ for $\mathrm{Pb} / \mathrm{Ca}$. Because sampled material is mixed with aspirated $1 \% \mathrm{HNO}_{3}$ in the introduction system, we blank-subtracted statolith intensity values with those of a $1 \% \mathrm{HNO}_{3}$ sample analyzed before each statolith. We characterized the instrument's limits of detection as $3 \times$ the SD of the blanks and calculated ratios to mean $\mathrm{Ca}$ intensities to obtain a $\mathrm{Me} / \mathrm{Ca}$ detection limit of $0.045 \mathrm{mmol} \mathrm{mol}^{-1}$ for $\mathrm{Mg} / \mathrm{Ca}, 1.43 \mu \mathrm{mol}$ $\mathrm{mol}^{-1}$ for $\mathrm{Cr} / \mathrm{Ca}, 1.94 \mu \mathrm{mol} \mathrm{mol}{ }^{-1}$ for $\mathrm{Mn} / \mathrm{Ca}, 0.19 \mathrm{mmol}$ $\mathrm{mol}^{-1}$ for $\mathrm{Sr} / \mathrm{Ca}, 0.61 \mu \mathrm{mol} \mathrm{mol}^{-1}$ for $\mathrm{Ba} / \mathrm{Ca}$, and $0.84 \mu \mathrm{mol} \mathrm{mol}{ }^{-1}$ for $\mathrm{Pb} / \mathrm{Ca}$.

Similar to the findings of Brophy et al. (2004) and Ruttenberg et al. (2005) for otoliths of various fishes, Doryteuthis opalescens statoliths appear to have enriched cores relative to non-core material for certain elements (Table 2). Therefore, we used elevated levels of $\mathrm{Mg}$ and $\mathrm{Mn}$ to determine which ablation pit in the vertical transect through the core region actually sampled the true core. We ablated a second vertical transect out from the core to sample the early larval period (i.e. 2nd pit). To maintain consistency in our characterization of the chemical signature corresponding to the 'early larval period' across samples, we selected the ablation pit from the 2nd vertical transect that was located at the same depth as the core ablation for any given statolith.

Statistical analyses. Elemental concentrations in statoliths are expressed as $\mathrm{Me} / \mathrm{Ca}$ in $\mathrm{mmol} \mathrm{mol}^{-1}$ or $\mu \mathrm{mol}$ $\mathrm{mol}^{-1}$. Any value below the detection limit that was zero or negative (blank subtraction procedures occasionally resulted in negative intensity values when ion concentrations were low) was dropped from further analyses. Values above detection limits, or below detection limits but positive, were retained.
In order to detect regional differences in the concentrations of particular elements and multi-element fingerprints, we performed univariate and multivariate analyses of variance (ANOVA, MANOVA). Separate tests were conducted for 2002 and 2003, because sufficient samples were not available for analysis from overlapping sites in both years. Prior to statistical testing, residuals were examined for normality and homogeneity among collection sites. To meet assumptions of the statistical tests, all analyses were performed on natural log transformed data. For paralarval statoliths, to test the effect of each element separately, we used ANOVA by site. We used MANOVA models to test for spatial differences in multi-element fingerprints. Collection site was used as a fixed factor in separate MANOVA models for each year. Pillai's Trace was chosen as the test statistic because it is more robust to small sample sizes, unequal cell sizes and situations where covariances are not homogeneous (Scheiner 1993). Tukey's HSD test was used to detect post hoc differences among means $(\alpha=0.05)$.

We also used discriminant function analyses (DFA) on paralarval data to visualize spatial differences between collection locations for 2002 and 2003, and to examine classification success for paralarvae from different samples. Cross validations were done using jackknife ('leave one out') procedures in SPSS (SPSS Inc). Significance of the DFA was estimated using a randomization procedure with 1000 runs (White \& Ruttenberg 2007). The p-value presented is for the null hypothesis that the observed reclassification success is no better than that expected by random chance. We also used the 2002 and 2003 paralarval core chemistry data as a training dataset in a DFA to classify the adults from 2001. Because the adults were sampled in a different year and at different sites than the paralarvae, we were primarily interested in ascertaining whether the adults fell within the same discriminant space as the paralarvae; we did not attempt to assign them back to any particular site of origin. Previous studies that have compared the otolith chemistry of natal (i.e. prepelagic) individuals with the otolith cores of juveniles

Table 2. Doryteuthis opalescens. Mean \pm SE Me/Ca concentrations in the statolith cores of adult and paralarvae and the 2nd pit of paralarvae from different sampling years. Sample size refers to the total number of squid samples analyzed. Shown in parentheses are the numbers of statolith samples with detectable concentrations of a given element

\begin{tabular}{|lccccccc|}
\hline Sample & $\begin{array}{c}\text { Sample } \\
\text { size }\end{array}$ & $\begin{array}{c}\mathrm{Mg} \\
\left(\mathrm{mmol} \mathrm{mol}^{-1}\right)\end{array}$ & $\begin{array}{c}\mathrm{Cr} \\
\left(\mu \mathrm{mol} \mathrm{mol}^{-1}\right)\end{array}$ & $\begin{array}{c}\mathrm{Mn} \\
\left(\mu \mathrm{mol} \mathrm{mol}^{-1}\right)\end{array}$ & $\begin{array}{c}\mathrm{Sr} \\
\left(\mathrm{mmol} \mathrm{mol}^{-1}\right)\end{array}$ & $\begin{array}{c}\mathrm{Ba} \\
\left(\mu \mathrm{mol} \mathrm{mol}^{-1}\right)\end{array}$ & $\begin{array}{c}\mathrm{Pb} \\
\left(\mu \mathrm{mol} \mathrm{mol}^{-1}\right)\end{array}$ \\
\hline 2001 adult core & 11 & $2.4 \pm 0.41(11)$ & $1.9 \pm 0.75(3)$ & $18.6 \pm 5.89(8)$ & $10.4 \pm 0.40(11)$ & $7.3 \pm 0.54(11)$ & $0.6 \pm 0.18(0)$ \\
2002 paralarval core & 27 & $1.6 \pm 0.08(27)$ & $1.9 \pm 1.22(11)$ & $16.7 \pm 3.73(24)$ & $10.4 \pm 0.24(27)$ & $9.9 \pm 0.63(27)$ & $1.8 \pm 0.53(19)$ \\
2003 paralarval core & 42 & $2.2 \pm 0.18(42)$ & $4.2 \pm 1.73(23)$ & $13.4 \pm 2.41(40)$ & $10.2 \pm 0.23(42) 10.0 \pm 0.71(42)$ & $1.0 \pm 0.14(27)$ \\
2002 paralarval 2nd pit & 29 & $0.66 \pm 0.07(29)$ & $2.1 \pm 0.59(11)$ & $2.5 \pm 0.56(22)$ & $10.1 \pm 0.37(29)$ & $7.3 \pm 0.40(29)$ & $1.3 \pm 0.38(22)$ \\
2003 paralarval 2nd pit & 41 & $0.73 \pm 0.08(41)$ & $2.3 \pm 0.55(20)$ & $2.3 \pm 0.74(24)$ & $9.7 \pm 0.33(41)$ & $6.5 \pm 0.32(41)$ & $0.9 \pm 0.19(27)$ \\
& & & & & & & \\
\hline
\end{tabular}


have found mixed results in terms of the degree of overlap in multi-element chemical signatures (Warner et al. 2005, Ruttenberg et al. 2008). If the adult core chemistry resembles that of the paralarvae, this technique may be used in future studies to assign adults back to source.

\section{RESULTS}

\section{Microchemistry of paralarval statoliths}

Doryteuthis opalescens paralarvae averaged 2 to $3 \mathrm{~mm}$ ML. Statoliths from these paralarvae measured approximately $200 \mu \mathrm{m}$ across the longest axis (Fig. 2); for some samples, a regular banding pattern of daily increments was observed similar to that reported in Butler et al. (1999). For paralarval statoliths from the 3 collection locations in 2002 and the 4 collection locations in 2003, we measured Me/Ca ratios and determined that 4 out of 6 elements had reliably detectable

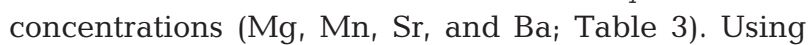
these 4 elements, we tested whether concentrations in the statolith core and 2nd pit (early pelagic life) were different among collection locations (Fig. 3A shows cores, Fig. 3B shows 2nd pit).

For natal core signatures, several elements showed significant spatial differences in one comparison or another (Table 4, Fig. 3A). In 2002, although no elements were significantly different among locations at $\mathrm{p}<0.05$, both $\mathrm{Ba}$ and $\mathrm{Mn}$ were marginally different ( $p=0.05$ and 0.08 , respectively). For $\mathrm{Ba}$, the values for the samples from Catalina (Cat) were higher than those from the site between Santa Barbara Island and Catalina (SBI-Cat) and the Santa Barbara Island (SBI) site (Tukey's HSD, p < 0.05) (see Fig. 1 \& Table 1 for all site locations). Although not significantly different, concentrations of $\mathrm{Mn}$ in the core were elevated for samples collected at Cat and SBI-Cat. For 2003 statolith cores, there were significant between-collection differences in $\mathrm{Sr}$ and Ba ratios (Table 4, Fig. 3A). Col- lection W from the Santa Cruz Channel (SCC-W) had high Sr and SCC-E and SCC-W had high Ba, while the sample from Redondo Canyon (Red) had low $\mathrm{Sr}$ and low Ba (Tukey's HSD, p < 0.05).

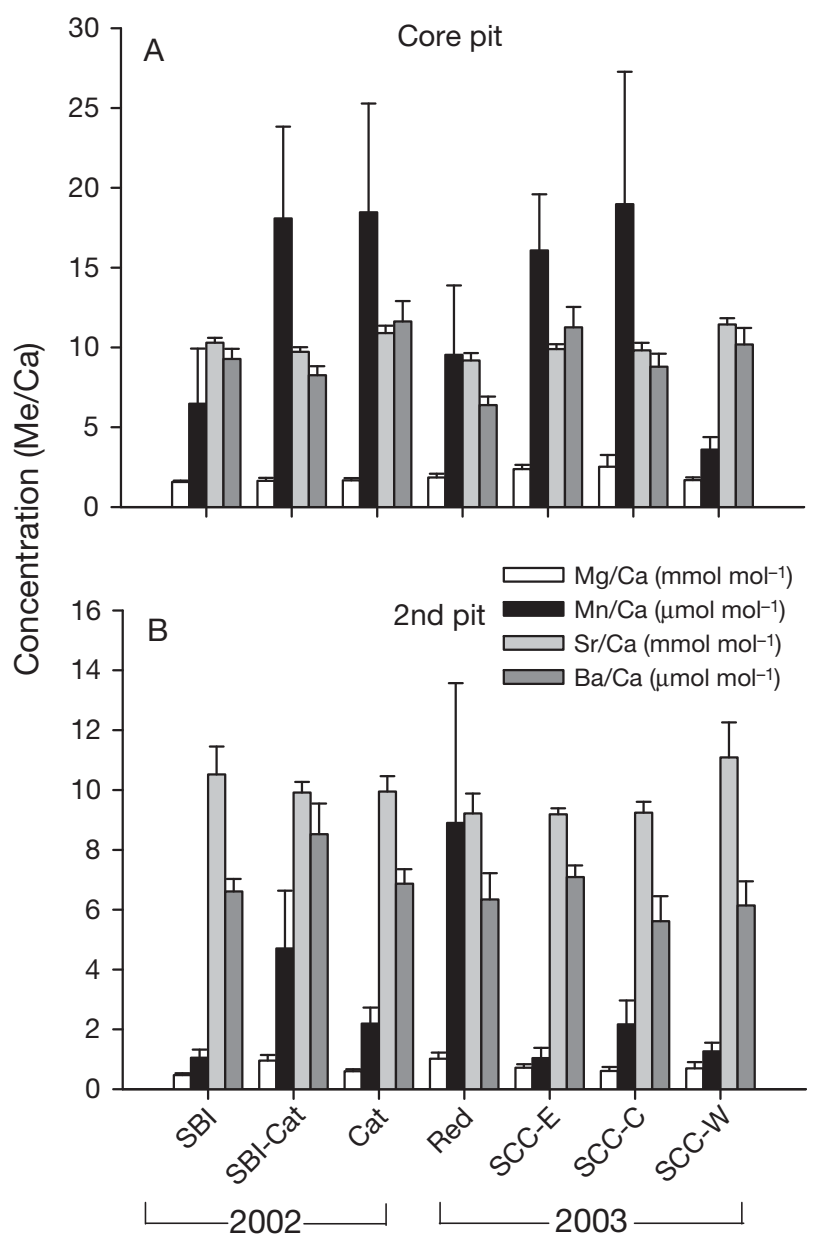

Fig. 3. Doryteuthis opalescens. Mean concentrations of trace elements in (A) core pits and (B) 2nd pits of paralarval statoliths from collections in 2002 and 2003. Shown are the element/calcium (Me/Ca) ratios for $\mathrm{Mg}, \mathrm{Mn}, \mathrm{Sr}$, and Ba. Values are means + SE. Note: $y$-axis scales differ. See Fig. 1 \& Table 1 for site details

Table 3. Doryteuthis opalescens. Number of statoliths analyzed from paralarval collections in 2002 and 2003, with percent of samples recording detectable levels of each element and percent of samples having Me/Ca concentrations greater than the limits of detection (LOD). Detectable levels were those in which counts $\mathrm{s}^{-1}$ of a particular element were positive in LA-ICPMS analyses. LOD were determined by analyzing blank solutions and were calculated as $3 \times$ SD of the blanks

\begin{tabular}{|c|c|c|c|c|c|c|c|c|c|c|c|c|c|}
\hline \multirow[t]{2}{*}{ Ablation pit } & \multirow{2}{*}{$\begin{array}{l}\text { Number of } \\
\text { statoliths }\end{array}$} & \multicolumn{6}{|c|}{$\%$ of samples with detectable levels } & \multicolumn{6}{|c|}{$\%$ of samples in which concentration $>$ LOD } \\
\hline & & $\mathrm{Mg}$ & $\mathrm{Cr}$ & Mn & $\mathrm{Sr}$ & $\mathrm{Ba}$ & $\mathrm{Pb}$ & $\mathrm{Mg}$ & $\mathrm{Cr}$ & $\mathrm{Mn}$ & $\mathrm{Sr}$ & $\mathrm{Ba}$ & $\mathrm{Pb}$ \\
\hline 2001 adult core & 11 & 100 & 27 & 73 & 100 & 100 & 55 & 100 & 0 & 64 & 100 & 100 & 0 \\
\hline 2002 paralarval core & 27 & 100 & 41 & 89 & 100 & 100 & 70 & 100 & 7 & 85 & 100 & 96 & 44 \\
\hline 2003 paralarval core & 42 & 100 & 52 & 95 & 100 & 100 & 64 & 100 & 29 & 90 & 100 & 100 & 64 \\
\hline 2002 2nd pit & 29 & 100 & 38 & 76 & 100 & 100 & 76 & 100 & 7 & 31 & 100 & 93 & 38 \\
\hline 2003 2nd pit & 42 & 100 & 45 & 50 & 100 & 98 & 64 & 95 & 10 & 19 & 100 & 98 & 31 \\
\hline
\end{tabular}


Using combined information from all elements detectable in statolith cores in a MANOVA, sites were marginally non-significantly different from one another in 2002 (Pillai's Trace $=0.564, F_{8,38}=1.86, \mathrm{p}=$ 0.09). In comparing all 4 collection sites for 2003, we found significant differences in the chemical signatures of statolith cores (Pillai's Trace $=0.65, F_{12,105}=$ $2.4, \mathrm{p}<0.008)$. The 3 sample sites in 2002 were within $44 \mathrm{~km}$ of each other, while the 4 sample sites in 2003 were within $131 \mathrm{~km}$ of each other. These differences can be visualized using DFA (Fig. 4). The 2002 core pit (natal signature) samples show a pattern of discrimination among sites of origin $(62.5 \%$ of cross-validated cases correctly classified, $\mathrm{p}=0.005)$, with $\mathrm{Sr}$ and $\mathrm{Mg}$ driving Function 1 and $\mathrm{Mn}$ and Ba affecting Function 2 (Fig. 4A). A weaker, but statistically significant pattern of discrimination among samples occurred in 2003 (42.5\% of cross-validated cases correctly classified, $\mathrm{p}=$ 0.04), driven primarily by $\mathrm{Sr}$ and $\mathrm{Mn}$ in Function 1, and by $\mathrm{Mg}$ and $\mathrm{Ba}$ in Function 2 (Fig. 4B). However, when the 3 SCC samples were combined, a stronger pattern of discrimination emerged among regions of origin (Red versus SCC) in 2003 (80.0\% of cross-validated [jackknifed] cases correctly classified), driven primarily by $\mathrm{Sr}$ in Function 1 and by Ba in Function 2 .

While elemental concentrations in the 2nd pit (early pelagic life) sections of the statolith were generally lower than in the natal core (Table 2), Mg and $\mathrm{Mn}$ ratios tended to show geographical differences among regions (Table 4, Fig. 3B). In 2002, Mg levels were higher for SBI-Cat than those from SBI, while the samples from Cat were intermediate (Tukey's HSD, $\mathrm{p}<0.05)$. Although Mn levels were marginally different in the core region among the 3 sites in 2002, a similar but non-significant pattern remained for the 2nd pit, with lower Mn concentrations at SBI than the other 2 sites (Tukey's HSD, p < 0.05). In 2003, samples from Red were significantly higher in
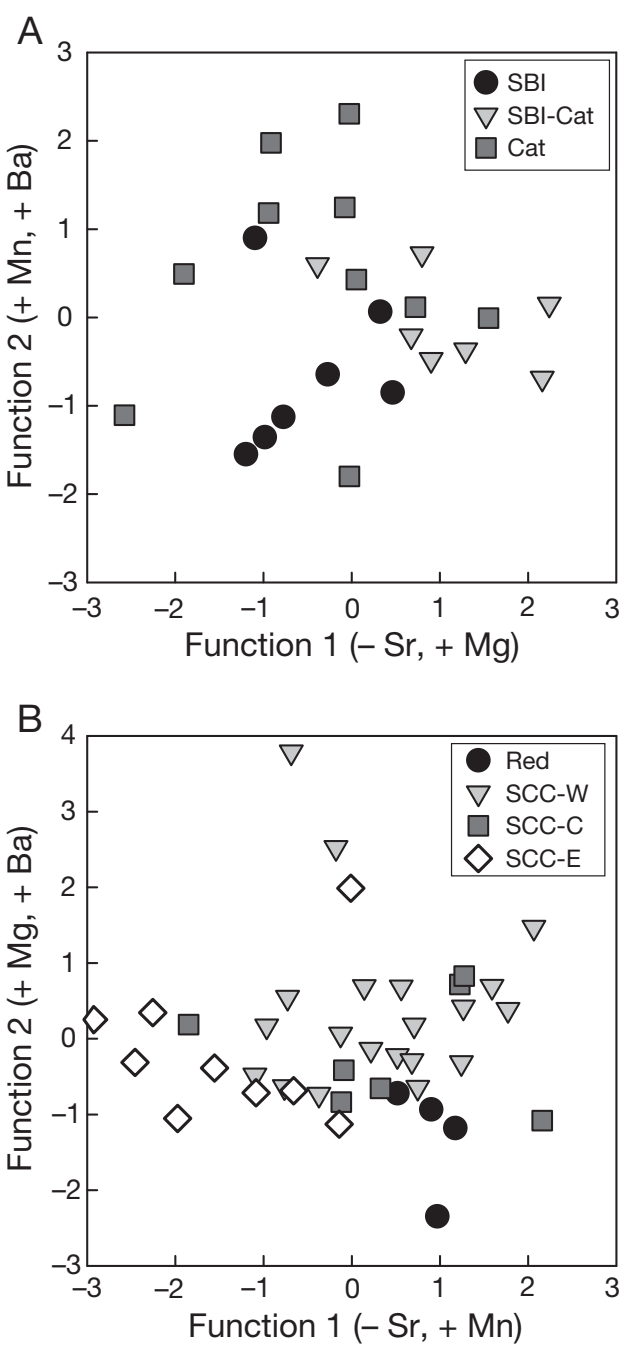

Fig. 4. Doryteuthis opalescens. Discriminant function analysis (DFA) of paralarval cores in (A) 2002 and (B) 2003 using Mg, $\mathrm{Mn}, \mathrm{Sr}$, and Ba. Jackknife values were $62.5 \%$ (A) and $42.5 \%$ (B). Reducing the sites to 2 regions in 2003 increased the reclassification success to $80.0 \%$. See Fig. 1 \& Table 1 for site details

Table 4. Doryteuthis opalescens. Region effect by year from univariate ANOVAs comparing trace element concentrations (expressed as $\mathrm{Me} / \mathrm{Ca}$, natural log transformed) in cores and 2nd pits of paralarval statoliths collected in 2002 and 2003.

Significant $p$-values are in bold

\begin{tabular}{|c|c|c|c|c|c|c|c|c|}
\hline \multirow{2}{*}{ Region } & \multicolumn{4}{|c|}{-2002} & \multicolumn{4}{|c|}{-2003} \\
\hline & $\mathrm{df}$ & MS & $F$ & $\mathrm{p}$ & $\mathrm{df}$ & MS & $F$ & $\mathrm{p}$ \\
\hline \multicolumn{9}{|l|}{ Cores } \\
\hline $\mathrm{Mg}$ & 2 & $2.969 \times 10^{-3}$ & 0.039 & 0.962 & 3 & 0.243 & 1.451 & 0.243 \\
\hline $\mathrm{Mn}$ & 2 & 4.420 & 2.773 & 0.085 & 3 & 2.349 & 1.669 & 0.191 \\
\hline $\mathrm{Sr}$ & 2 & $2.713 \times 10^{-2}$ & 2.093 & 0.145 & 3 & $7.275 \times 10^{-2}$ & 4.701 & 0.007 \\
\hline $\mathrm{Ba}$ & 2 & 0.224 & 3.317 & 0.053 & 3 & 0.365 & 3.656 & 0.021 \\
\hline \multicolumn{9}{|l|}{ 2nd pit } \\
\hline $\mathrm{Mg}$ & 2 & 0.911 & 5.038 & 0.014 & 3 & 0.426 & 1.510 & 0.228 \\
\hline Mn & 2 & 2.434 & 2.227 & 0.135 & 3 & 2.780 & 4.058 & 0.024 \\
\hline $\mathrm{Sr}$ & 2 & $5.668 \times 10^{-3}$ & 0.190 & 0.828 & 3 & $5.881 \times 10^{-2}$ & 2.059 & 0.122 \\
\hline $\mathrm{Ba}$ & 2 & 0.131 & 2.144 & 0.137 & 3 & 0.145 & 1.540 & 0.220 \\
\hline
\end{tabular}



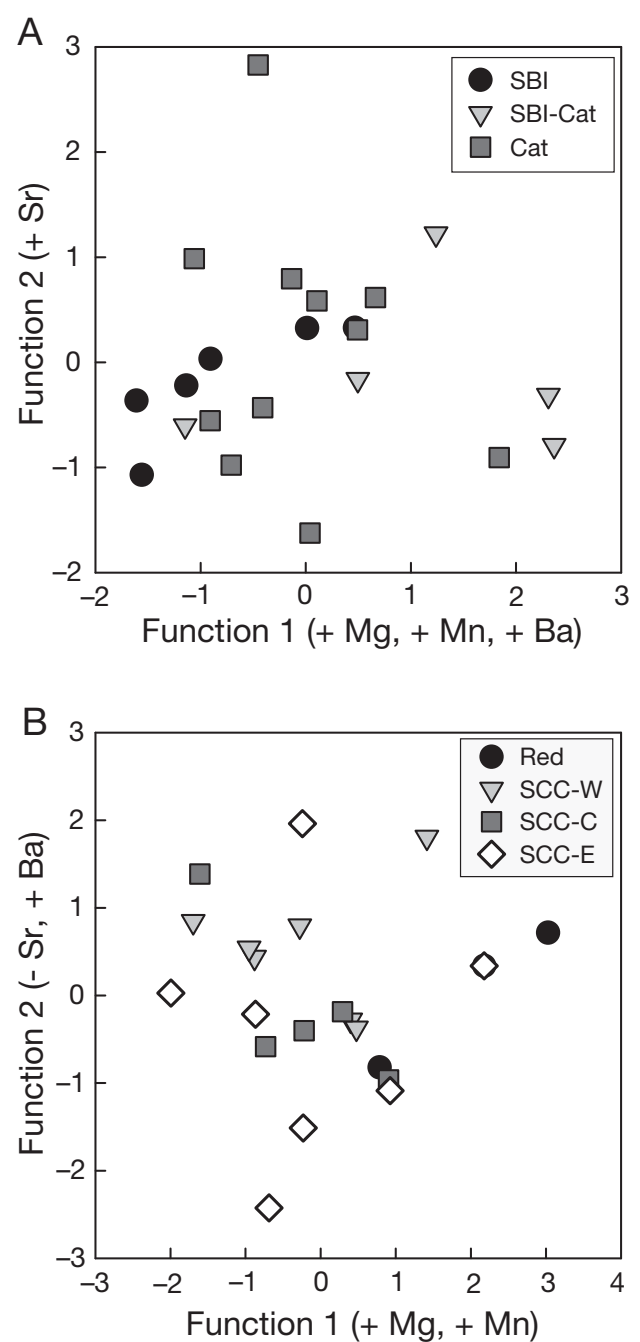

Fig. 5. Doryteuthis opalescens. DFA of paralarval 2nd pits in (A) 2002 and (B) 2003 using Mg, Mn, Sr, and Ba. Jackknife values were $31.8 \%$ (A) and $42.9 \%$ (B). Reducing the sites to 2 regions in 2003 increased the reclassification success to $81.0 \%$. See Fig. 1 \& Table 1 for site details

Mn than samples from the SCC locations in the 2nd pit (Table 4, Fig. 3B).

A MANOVA that combined elemental data for the 2nd pit (early pelagic life) sections suggested that regions were neither significantly different from one another in 2002 (Pillai's Trace $=0.353, F_{8,34}=0.911, \mathrm{p}=$ 0.52 ), nor in 2003 (Pillai's Trace $=0.818, F_{12,48}=1.49$, $\mathrm{p}=0.16)$. DFA for the 2002 samples showed a weak and non-significant pattern of discrimination among the 2nd pits $(31.8 \%$ of crossvalidated [jackknifed] cases correctly classified, $\mathrm{p}=0.59$ ), with $\mathrm{Mg}$ driving Function 1 and Sr affecting Function 2 (Fig. 5A). A stronger, yet still non-significant pattern of discrimination among 2nd pits occurred in 2003 (42.9\% of crossvalidated [jackknifed] cases correctly classified, $\mathrm{p}=$ 0.08), driven primarily by $\mathrm{Mn}$ in Function 1 and by $\mathrm{Sr}$ and Ba in Function 2 (Fig. 5B). However, combining the 3 Santa Cruz Channel samples into 1 group resulted in a much stronger pattern of discrimination among regions of origin in $2003(81.0 \%$ of cross-validated [jackknifed] cases correctly classified), driven primarily by Mn in Function 1 and by Ba in Function 2 .

\section{Microchemistry of adult statoliths}

To use statolith chemistry to track larval dispersal and adult migration, elemental signatures of statolith cores of adults spawned at a given site should match those of natal statoliths produced at that site. At the very least, there should be a strong similarity in the concentration of trace elements in the cores (natal signature) of the paralarvae and the cores of adults that were likely spawned at some of the same sites. Despite being collected in a different year (2001) and from different locations, laser ablations of adult statoliths showed a pattern of trace element levels similar to that of paralarvae, with core enrichments of $\mathrm{Mn}$ and detectable levels of $\mathrm{Mg}, \mathrm{Sr}$, and $\mathrm{Ba}$ (Tables 2 \& 3). In every case, average values of $\mathrm{Me} / \mathrm{Ca}$ concentrations for individual elements in adult statolith cores fell within the range of those same elements measured in paralarval cores (Fig. 6). However, average concentrations of trace metals differed significantly between the paralarval and adult cores, and this pattern was driven primarily by differences in Ba (Table 5). Adult statolith cores contained a significantly lower average concentration of $\mathrm{Ba}$, but exact matches of elemental values were not expected. These adults are likely to have origins different from the paralarval samples and, overall,

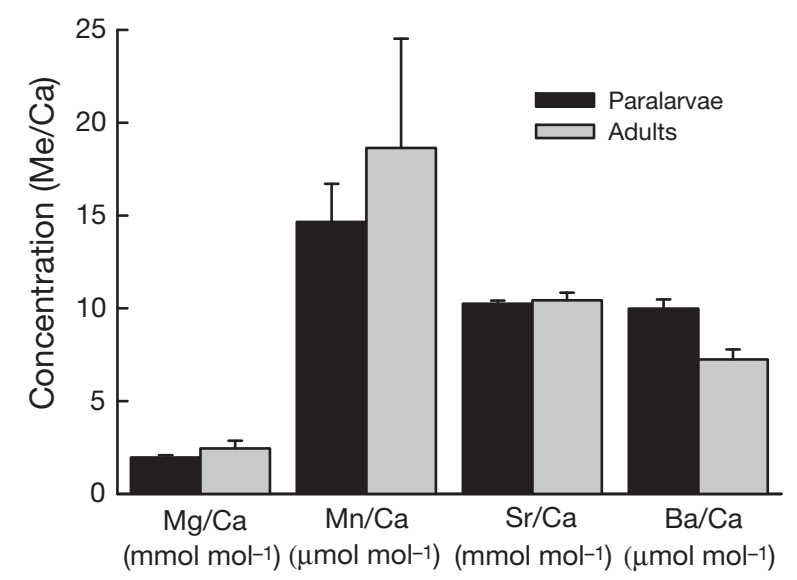

Fig. 6. Doryteuthis opalescens. Mean concentrations of trace elements in statolith cores of paralarvae from both years $(\mathrm{n}=$ $69)$ and adult squid $(n=11)$. In general, paralarvae and adults have similar trace elemental concentrations in the natal portion of the statolith. Shown are the $\mathrm{Me} / \mathrm{Ca}$ ratios for $\mathrm{Mg}, \mathrm{Mn}$, $\mathrm{Sr}$, and Ba. Values are means $+\mathrm{SE}$ 
Table 5. Doryteuthis opalescens. Results from MANOVA and univariate ANOVA comparing trace element concentrations (expressed as $\mathrm{Me} / \mathrm{Ca}$, natural $\log$ transformed) in the statolith cores of paralarvae from both years and adult market squid. Significant p-values are in bold

\begin{tabular}{|lccccc|}
\hline MANOVA & Pillai's Trace & Hypothesis df & Error df & $F$ & $p$ \\
\hline All elements & 0.148 & 4 & 67 & 2.898 & $\mathbf{0 . 0 2 8}$ \\
ANOVA & df & MS & $F$ & p \\
\hline Mg & 1 & 0.264 & 0.050 & 0.823 \\
Mn & 1 & 1.571 & 0.888 & 0.349 \\
Sr & 1 & $1.695 \times 10^{-2}$ & 0.226 & 0.636 \\
Ba & 1 & $9.783 \times 10^{-2}$ & 8.282 & $\mathbf{0 . 0 0 5}$ \\
\hline
\end{tabular}

the natal region of origin of adult squid captured on spawning grounds. However, a few adult core samples (primarily those from Catalina) fell at the edge and just outside of the discriminant space generated by the paralarvae. This mismatch may have arisen because the adults were sampled in a different year and at sites different from the paralarval collections. To correctly assess population connectivity, collections of adults need to be made from the likely cohorts corresponding to ripe eggs or paralarvae collected previously. Interestingly,

Ba levels could vary from year to year. In addition, these differences could reflect a sampling artifact in that only 11 adult samples were available for analysis.

We used the 2002 and 2003 paralarval samples as a training data set in a DFA to classify the adult squid samples from 2001. We found that the adult cores fell within approximately the same discriminant space as those of the paralarval cores (Fig. 7), suggesting that, in the future, this technique may allow us to identify

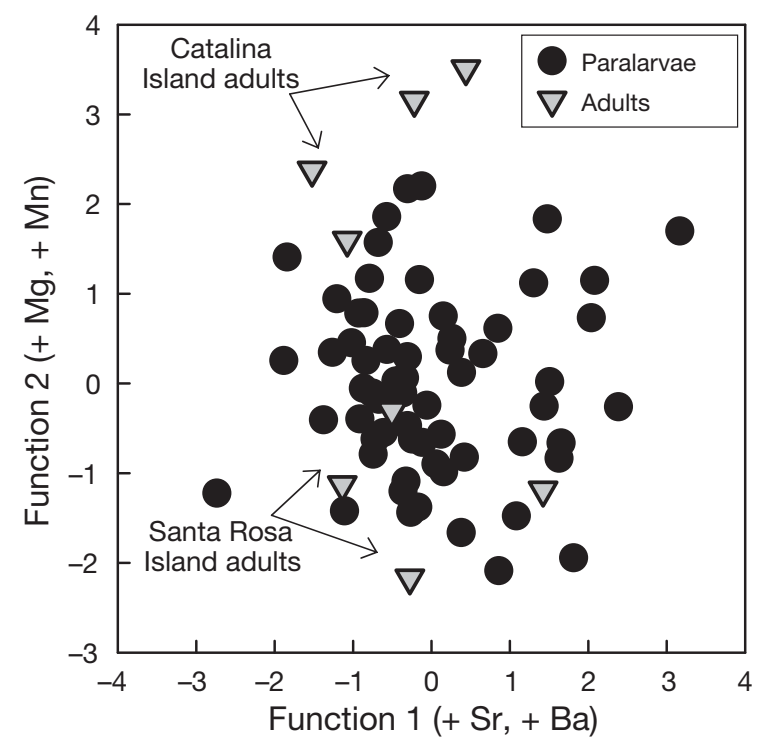

Fig. 7. Doryteuthis opalescens. DFA of paralarvae and adult statolith cores showing that adults from 2001 generally lie in the same DFA space as the paralarvae collected in 2002 and 2003. The discriminant functions were generated using the core concentrations of $\mathrm{Mg}, \mathrm{Mn}, \mathrm{Sr}$, and $\mathrm{Ba}$ of paralarvae. Adult cores were then classified using these discriminant functions. Adult core signatures from 2 different collection locations (identified by arrows) fall out in distinct groups in DFA space. Three adult squid were excluded because Mn values were below detectable levels. Jackknife reclassification success is $42.9 \%$. See Fig. 1 for locations of Santa Catalina and Santa Rosa Islands elemental signatures of statolith cores of adult squid collected south of Santa Rosa Island and south of Catalina Island fell into distinct groups (100\% of crossvalidated cases correctly classified, Fig. 7), raising the possibility that adults from these 2 collection locations may differ in their origin. Some caution needs to be exercised here, however, because sample sizes were small for this comparison.

\section{DISCUSSION}

By analyzing the chemical concentrations of a suite of trace elements contained within the core pit (natal region) and 2nd pit (early larval portion) of statoliths, we have shown geographic differences in elemental fingerprints of market squid paralarvae collected at distances of $100 \mathrm{~km}$ in 2 separate years. Poor spatial discrimination occurred in some comparisons, potentially because of the close proximity of collection sites and low sample sizes in any one year. We have also demonstrated that the core area of a statolith can be sampled in adult squid, with detectable levels of trace elements that are within the range of measured values detected in the paralarvae. Despite sampling different locations in different years, the multi-element chemical signatures of adults were fairly similar to those of the paralarvae, suggesting that future studies may be able to assign adults back to a location of origin. While natal chemical signatures have previously been assessed in hard parts of other mollusks (e.g. Becker et al. 2005, Zacherl 2005, Doubleday et al. 2008), to our knowledge this is the first study to analyze the chemical composition of statoliths from squid paralarvae and the first to assess the potential to detect geographical structure in natal statolith signatures of a commercially important cephalopod. Using these techniques to investigate population connectivity for fisheries management will be improved by repeated sampling of sites to estimate temporal levels of chemical variation 
and by sampling over an expanded spatial domain (i.e. focusing on the 3 major fishing grounds from Central to Southern California).

\section{Trace element enrichment in statolith cores}

We detected differences in the levels of trace elements between the core and early larval portions of squid statoliths, with core enrichment of $\mathrm{Mn}$ and $\mathrm{Mg}$ (Table 2). This is the first study to report core enrichment in statoliths. Similar patterns of core enrichment of $\mathrm{Mn}, \mathrm{Mg}$, and Ba have been reported for fish otoliths across a number of phylogenetically distinct species (Brophy et al. 2004, Ruttenberg et al. 2005, Warner et al. 2005). Consistent evidence of core enrichment indicates that this phenomenon may be attributed to common physiological or maternal effects (Thorrold et al. 2006), although actual elemental concentrations may be influenced by local environmental conditions. In contrast to studies of fish otoliths (e.g. Ruttenberg et al. 2005), we did not find evidence for core enrichment of Ba in squid statoliths. Elements such as Mn may be concentrated in the core and required for biomineralization processes, especially the initial nucleation steps for aragonite crystal formation. Other elements such as Sr may also be critical for normal statolith development in cephalopods (Hanlon et al. 1989). Despite consistent core enrichment of $\mathrm{Mn}$ across all samples, we also detected spatial differences in Mn concentrations, both in the natal and early larval portions of squid statoliths; these may be a result of spatial differences in water chemistry or maternal effects.

\section{Spatial patterns of statolith chemistry}

Spatial differences in upwelling and temperature, resulting from the complex oceanography of the Southern California Bight, can affect water chemistry and the incorporation of trace metals into mineralized hard parts such as statoliths. In 2003, levels of Ba and $\mathrm{Sr}$ in statolith cores were significantly higher at sites that tend to have colder water temperatures (the Santa Cruz Channel) relative to the Redondo Canyon site. Zacherl (2005) found that Ba/Ca and Sr/Ca concentrations in natal statoliths of the gastropod Kelletia kelletii were inversely related to the temperature recorded at particular sites along the California coast. In agreement with extensive research on fish otoliths (e.g. Campana 1999, Bath et al. 2000, Elsdon \& Gillanders 2002), many studies of the chemical composition of cephalopod statoliths have reported a dependence of Sr incorporation on temperature (Ikeda et al. 1998, Arkhipkin et al. 2004).
Market squid paralarvae are abundant close to shore for up to a month after hatching, and it has been suggested that they may be entrained nearshore (i.e. within 1 to $3 \mathrm{~km}$ of the coast) by a combination of vertical diel migration and tidally reversing currents (Zeidberg \& Hamner 2002). Therefore, large-scale mixing of paralarvae from geographically distant natal sources (e.g. island to island) may not commonly occur, presenting the possibility that paralarvae from our sample locations may have hatched from relatively nearby sources. The significant reclassification success of statolith cores from 2002 and 2003 supports the notion that many squid paralarvae have stayed together since birth. However, previous evidence of elevated abundances of paralarvae in the lee of some islands suggests that oceanographic forces may sometimes entrain and mix larvae from different sources (Zeidberg \& Hamner 2002). The strong tidally induced flow that occurs between islands in the Santa Cruz Channel (J. E. Caselle unpubl. data) may have served to mix aggregations of squid paralarvae, and these processes could have contributed to the weak reclassification success in 2003, since our net tows captured paralarvae that likely hatched 2 to 4 wk previously. By reducing the 3 Santa Cruz Channel sites to one group, spatial discrimination among regions (SCC versus Red) improved dramatically. In general, stronger spatial discrimination was found for natal regions (i.e. core) than the early larval portions (i.e. 2nd pit) of paralarval statoliths. Because of the close proximity of sampling locations each year, the paralarvae may have been entrained in chemically similar water masses at that point of development. Elevated elemental concentrations in the core and spatial differences in maternal contributions may have also contributed to the improved spatial discrimination of natal chemical signatures over the early larval signatures.

Other studies in this region have reported spatial differences in the elemental fingerprints of the natal portion of fish otoliths, gastropod statoliths, and larval bivalve shell material collected from different geographic locations. On a similar scale to the current study, Warner et al. (2005) detected significant geographic discrimination among the natal otoliths from the kelp rockfish Sebastes atrovirens at sites in the northern Channel Islands and the mainland Santa Barbara coast. Zacherl (2005) reported significant discrimination in the chemical signatures of larval Kelletia kelletii statoliths from 3 distinct regions at a slightly larger spatial scale, and those differences were temporally consistent over a 3-yr period. By analyzing the elemental fingerprints of the larval shell material of 2 species of mussel (Mytilus californianus and M. galloprovincialis), Becker et al. (2005) were able to discriminate among samples collected from bays and 2 open 
coast regions in southern California, and those signatures were relatively stable over weeks and months. These results and ours point to the utility of LA-ICPMS as a technique to identify the sites and/or regions of origin of a number of groups of marine organisms, including commercially important species.

\section{Stock identification and mixing - a path to solving the problem}

One major uncertainty, critical for the management of market squid, is the extent to which geographically distant populations are either separated or well-connected over ecological timescales. Do squid home back to the spawning grounds where they hatched, or is there extensive mixing and little natal homing as squid migrate offshore to feed? As mentioned above, the peak of squid spawning and the main fishing activity occur in different seasons in northern and southern California; the northern fishery typically occurs from April to November, while the southern fishery runs from October to April (Zeidberg et al. 2006). Although it is generally assumed that the seasonal shift in peak spawning between central and southern California is attributable to spatial differences in ocean bottom temperatures (CDFG 2005) or the productive season (Zeidberg et al. 2006), these geographic differences in spawning activity suggest that there may be at least 2 separate populations. The characterization of elemental fingerprints of natal statoliths and those of returning adults-employing the techniques described in this paper-may help to address critical questions regarding stock identification along the California coast. The weak discriminatory ability, particularly for the 2003 paralarvae, may be due in part to the close spatial proximity of collection sites and the potential for mixing among those sites in the time between hatching and collection ( 2 wk). Targeted collections of prerelease embryos from the 3 major fishing grounds (i.e. Catalina, Northern Channel Islands, and Monterey) should improve the ability to discriminate the geographic region of origin of embryos and returning adults in future studies.

Other studies have successfully used techniques in statolith chemistry to identify stocks of commercially important squid. For example, using whole statolith solution-based ICPMS, Arkhipkin et al. (2004) identified geographic differences in statolith chemical signatures from different putative stocks of Doryteuthis (= Loligo) gahi in the South Atlantic. They also detected distinct seasonal differences in chemical signatures between autumn and spring spawned cohorts off the Falkland Islands, suggesting that they developed in different environments. In addition, Doubleday et al.
(2008) recently showed distinct population structure in Octopus maorum populations in Tasmania by analyzing the elemental concentrations in the natal portion of their stylet. A high classification success among regions suggested low levels of population exchange.

In the present study, we found significant spatial discrimination of statolith cores of squid paralarvae based on their multi-elemental fingerprints. The chemical signatures of adult statolith cores contained equivalent levels of trace metals and closely matched those of paralarvae, despite being sampled in a different year. In the future, a spatial atlas of chemical signatures could be generated from simultaneous collections of paralarvae in different regions, or, even better, collections of ripe egg cases containing developing embryos. Laboratory rearing has revealed that Doryteuthis opalescens develops statoliths prior to hatching (Fields 1965, Hanlon et al. 1989), and those statoliths from known natal sources can be isolated and prepared for LA-ICPMS analysis using techniques similar to those reported for gastropod egg capsules (Zacherl 2005). Finally, by matching the elemental fingerprints of adult cores (collected on spawning grounds $~ 6$ mo after collections of ripe eggs) with those of paralarval statoliths, we could begin to assess the degree to which market squid populations are either segregated into separate stocks or well-mixed on ecological timescales.

Acknowledgements. This work was supported by the Partnership for Interdisciplinary Studies of Coastal Oceans (PISCO), funded jointly by the David and Lucile Packard Foundation and the Gordon and Betty Moore Foundation. Financial support was also provided by a Monterey Bay Aquarium Research Institute postdoctoral fellowship (funded by the David and Lucile Packard Foundation), California Sea Grant (R/F-95-PD-F-1/1), by the Coastal Environmental Quality Initiative (CEQI, funded by the University of California Marine Council) and by NOAA/IOOS Grant \#20073439. We thank G. Paradis, D. Zacherl, and R. J. Barr for technical assistance and advice, and J. A. T. Booth for help with Fig. 1. We also thank CDFG for providing adult samples. The manuscript was improved by the comments of 3 anonymous reviewers. This is PISCO Contribution 333.

\section{LITERATURE CITED}

Ally JRR, Keck SA (1978) A biochemical-genetic population study of market squid, Loligo opalescens, along the California coast. Calif Fish Game Fish Bull 169:113-122

Anderson FE (2000) Phylogenetic relationships among loliginid squids (Cephalopoda: Myopsida) based on analyses of multiple data sets. Zool J Linn Soc 130:603-633

Arkhipkin AI, Campana SE, Fitzgerald J, Thorrold SR (2004) Spatial and temporal variation in elemental signatures of statoliths from the Patagonian longfin squid (Loligo gahi). Can J Fish Aquat Sci 61:1212-1224

> Bath GE, Thorrold SR, Jones CM, Campana SE, McLaren JW, Lam JWH (2000) Strontium and barium uptake in aragonitic otoliths of marine fish. Geochim Cosmochim Acta 64: 1705-1714 
Becker BJ, Fodrie FJ, McMillan PA, Levin LA (2005) Spatial and temporal variation in trace elemental fingerprints of mytilid mussel shells: a precursor to invertebrate larval tracking. Limnol Oceanogr 50:48-61

Bettencourt V, Guerra A (2000) Growth increments and biomineralization process in cephalopod statoliths. J Exp Mar Biol Ecol 248:191-205

Brophy D, Jeffries TE, Danilowicz BS (2004) Elevated manganese concentrations at the cores of clupeid otoliths: possible environmental, physiological, or structural origins. Mar Biol 144:779-786

Butler J, Fuller D, Yaremko M (1999) Age and growth of market squid (Loligo opalescens) of California during 1998. Calif Coop Ocean Fish Invest Rep 40:191-195

Campana SE (1999) Chemistry and composition of fish otoliths: pathways, mechanisms and applications. Mar Ecol Prog Ser 188:263-297

Campana SE, Thorrold SR (2001) Otoliths, increments, and elements: Keys to a comprehensive understanding of fish populations? Can J Fish Aquat Sci 58:30-38

CDFG (California Department of Fish and Game) (2005) Final market squid fishery management plan. California Department of Fish and Game, Marine Region, Sacramento, CA

Christofferson JP, Foss A, Lambert WE, Welge B (1978) An electrophoretic study of select proteins from the market squid, Loligo opalescens Berry. Calif Fish Game Fish Bull 169:123-134

> Doubleday ZA, Pecl GT, Semmens JM, Danyushevsky L (2008) Using stylet elemental signatures to determine the population structure of Octopus maorum. Mar Ecol Prog Ser 360:125-133

Elsdon TS, Gillanders BM (2002) Interactive effects of temperature and salinity on otolith chemistry: challenges for determining environmental histories of fish. Can J Fish Aquat Sci 59:1796-1808

Elsdon TS, Gillanders BM (2003) Relationship between water and otolith elemental concentrations in juvenile black bream Acanthopagrus butcheri. Mar Ecol Prog Ser 260: 263-272

Fields WG (1965) The structure, development, food relations, reproduction, and life history of the squid Loligo opalescens Berry. Calif Fish Game Fish Bull 131:1-108

Hanlon RT, Bidwell JP, Tait R (1989) Strontium is required for statolith development and thus normal swimming behavior of hatchling cephalopods. J Exp Biol 141:187-195

Hurley AC (1977) Mating behavior of the squid Loligo opalescens. Mar Behav Physiol 4:195-203

Ikeda Y, Arai N, Skamoto W, Kidokoro H, Yoshida K (1998) Microchemistry of the statoliths of the Japanese common squid Todarodes pacificus with special reference to its relation to the vertical temperature profiles of squid habitat. Fish Sci 64:179-184

Ikeda Y, Okazaki J, Sakurai Y, Sakamoto W (2002) Periodic variation in $\mathrm{Sr} / \mathrm{Ca}$ ratios in statoliths of the Japanese Common Squid Todarodes pacificus Steenstrup, 1880 (Cephalopoda: Ommastrephidae) maintained under constant water temperature. J Exp Mar Biol Ecol 273:161-170

Ikeda Y, Arai N, Kidokoro H, Sakamoto W (2003) Strontium: calcium ratios in statoliths of Japanese common squid Todarodes pacificus (Cephalopoda: Ommastrephidae) as indicators of migratory behavior. Mar Ecol Prog Ser 251: 169-179

Jackson GD, Domeier ML (2003) The effects of an extraordinary El Niño/La Niña event on the size and growth of the squid Loligo opalescens off Southern California. Mar Biol 142:925-935
Jones GP, Milicich MJ, Emslie MJ, Lunow C (1999) Selfrecruitment in a coral reef fish population. Nature 402: 802-804

Kashiwada J, Recksiek CW (1978) Possible morphological indicators of population structure in the market squid, Loligo opalescens. Calif Fish Game Fish Bull 169:99-112

Lipinski MR (1993) The deposition of statoliths: a working hypothesis. In: Okutani T, O'dor R, Kubodera T (eds) Recent advances in cephalopod fishery biology. Tokai University Press, Tokyo, p 241-262

> Lloyd DC, Zacherl DC, Walker S, Paradis G, Sheehy M, Warner RR (2008) Egg source, temperature and culture seawater affect elemental signatures in Kelletia kelletii larval statoliths. Mar Ecol Prog Ser 353:115-130

Macewicz BJ, Hunter JR, Lo NCH, LaCasella EL (2004) Fecundity, egg deposition, and mortality of market squid (Loligo opalescens). Fish Bull 102:306-327

Radtke RL (1983) Chemical and structural characteristics of statoliths from the short-finned squid Illex illecebrosus. Mar Biol 76:47-54

Reichow D, Smith MJ (2001) Microsatellites reveal high levels of gene flow among populations of the California squid Loligo opalescens. Mol Ecol 10:1101-1109

Reiss CS, Maxwell MR, Hunter JR, Henry A (2004) Investigating environmental effects on population dynamics of Loligo opalescens in the Southern California Bight. Calif Coop Ocean Fish Invest Rep 45:87-97

Ruttenberg BI, Hamilton SL, Hickford $\mathrm{MJH}$, Paradis GL and others (2005) Elevated levels of trace elements in cores of otoliths and their potential for use as natural tags. Mar Ecol Prog Ser 297:273-281

> Ruttenberg BI, Hamilton SL, Warner RR (2008) Spatial and temporal variation in the natal otolith chemistry of a Hawaiian reef fish: prospects for measuring population connectivity. Can J Fish Aquat Sci 65:1181-1191

Scheiner SM (1993) MANOVA: multiple response variables and multispecies interactions. In: Scheiner SM, Gurevitch $\mathrm{J}$ (eds) Design and analysis of ecological experiments. Chapman \& Hall, New York, p 94-112.

Secor DH, Henderson-Arzapalo A, Piccoli PM (1995) Can otolith microchemistry chart patterns of migration and habitat utilization in anadromous fishes? J Exp Mar Biol Ecol 192:15-34

Sweetnam D (2006) Review of some California fisheries for 2005: coastal pelagic finfish, market squid, Dungeness crab, sea urchin, abalone, Kellet's whelk, groundfish, highly migratory species, ocean salmon, nearshore livefish, Pacific herring, and white seabass. Calif Coop Ocean Fish Invest Rep 47:9-29

Thorrold SR, Latkoczy C, Swart PM, Jones CM (2001) Natal homing in a marine fish metapopulation. Science 291: 297-299

Thorrold SR, Jones GP, Hellberg ME, Burton RS and others (2002) Quantifying larval retention and connectivity in marine populations with artificial and natural markers. Bull Mar Sci 70:291-308

> Thorrold SR, Jones GP, Planes S, Hare JA (2006) Transgenerational marking of embryonic otoliths in marine fishes using barium stable isotope. Can J Fish Aquat Sci 63: 1193-1197

Vidal EAG, DiMarco FP, Wormuth JH, Lee PG (2002) Influence of temperature and food availability on survival, growth, and yolk utilization of hatching squid. Bull Mar Sci 71:915-931

Vojkovich M (1998) The California fishery for market squid (Loligo opalescens). Calif Coop Ocean Fish Invest Rep 39:55-60 
Warner RR, Swearer SE, Caselle JE, Sheehy MS, Paradis GL (2005) Natal trace-elemental signatures in the otoliths of an open-coast fish. Limnol Oceanogr 50: 1529-1542

White JW, Ruttenberg BI (2007) Discriminant function analysis in marine ecology: some oversights and their solutions. Mar Ecol Prog Ser 329:301-305

Yang WT, Hixon RF, Turk PE, Krejci ME, Hulet WH, Hanlon RT (1986) Growth, behavior, and sexual maturation of the market squid, Loligo opalescens cultured through its life cycle. Fish Bull (Wash DC) 84:771-798

- Yatsu A, Mochioka N, Morishita K, Toh H (1998) Strontium/ calcium ratios in statoliths of the neon flying squid, Ommastrephes bartami (Cephalopoda), in the North Pacific Ocean. Mar Biol 131:275-282

Zacherl DC (2005) Spatial and temporal variation in statolith and protoconch trace elements as natural tags to track larval dispersal. Mar Ecol Prog Ser 290:145-163

Zacherl DC, Paradis G, Lea DW (2003a) Barium and strontium uptake into larval protoconchs and statoliths of the marine neogastropod Kelletia kelletii. Geochim Cosmochim Acta 67:4091-4099

Editorial responsibility: Hans Heinrich Janssen, Oldendorf/Luhe, Germany
Zacherl DC, Manríquez PH, Paradis GL, Day RW and others (2003b) Trace elemental fingerprinting of gastropod statoliths to study larval dispersal trajectories. Mar Ecol Prog Ser 248:297-303

Zeidberg LD (2004) Allometry measurements can determine the size and swimming speeds of juvenile and adult Loligo opalescens (Cephalopoda: Myopsida) squid from in situ video. J Exp Biol 207:4195-4203

Zeidberg LD, Hamner WM (2002) Distribution of squid paralarvae, Loligo opalescens (Cephalopoda: Myopsida), in the Southern California Bight in the three years following the 1997 El Niño. Mar Biol 141: $111-122$

Zeidberg LD, Hamner WM, Nezlin NP, Henry A (2006) The fishery for California market squid (Loligo opalescens) (Cephalopoda: Myopsida) from 1981 through 2003. Fish Bull (Wash DC) 104:46-59

Zumholz K, Klugel A, Hansteen T, Piatkowski U (2007) Statolith microchemistry traces the environmental history of the boreoatlantic armhook squid Gonatus fabricii. Mar Ecol Prog Ser 333:195-204

Submitted: May 22, 2008; Accepted: December 19, 2008 Proofs received from author(s): March 19, 2009 